\title{
Multiple dimensions of urban well-being: Evidence from India
}

S. Chandrasekhar

Abhiroop Mukhopadhyay

Follow this and additional works at: https://knowledgecommons.popcouncil.org/departments_sbsr-pgy

Part of the Demography, Population, and Ecology Commons, Family, Life Course, and Society Commons, International Public Health Commons, and the Migration Studies Commons How does access to this work benefit you? Let us know!

\section{Recommended Citation}

Chandrasekhar, S. and Abhiroop Mukhopadhyay. 2008. "Multiple dimensions of urban well-being: Evidence from India," Poverty, Gender, and Youth Working Paper no. 11. New York: Population Council. 


\section{POVERTY, GENDER, AND YOUTH}

\section{Multiple Dimension of Urban Well-Being: Evidence from India}

S. Chandrasekhar and Abhiroop Mukhopadhyay 


\section{(1) Population Council}

One Dag Hammarskjold Plaza

New York, New York 10017 USA

www.popcouncil.org

pubinfo@popcouncil.org

For information on Poverty, Gender, and Youth working papers, see www.popcouncil.org/publications/wp/index.html

This material may not be reproduced without written permission from the authors.

ISSN: $1554-8538$

(C) 2008 The Population Council, Inc. 


\title{
Multiple Dimensions of Urban Well-Being: Evidence from India
}

\author{
S. Chandrasekhar \\ Abhiroop Mukhopadhyay
}

S. Chandrasekhar is Fred H. Bixby Fellow, Population Council, New York, and Assistant Professor, Indira Gandhi Institute of Development Research, Mumbai, India. E-mail: chandra@igidr.ac.in. Abhiroop Mukhopadhyay is Lecturer, Indian Statistical Institute, New Delhi, India. E-mail: abhiroop@isid.ac.in

The second author received a grant facilitating his visit to Indira Gandhi Institute of Development Research from the "Capacity Development Programme: Strengthening State Plans for Human Development." We thank Mark Montgomery for detailed comments on an earlier draft. We are grateful for useful discussions with Nicolas Gravel; comments from participants at the Workshop on Poverty Measurement and Analysis, African Population and Health Research Centre, Kenya, and at the 2008 Annual Conference of the Indian Econometric Society; and from seminar participants at Indira Gandhi Institute of Development Research, Pace University, and the Population Council. 


\begin{abstract}
This paper addresses differences in outcomes across households residing in slums and non-slum urban areas of India. Using a nationally representative household data set, we undertake a robust multidimensional evaluation of intracity differences in well-being. We first established that if utility is defined as access to public goods such as water and sanitation, then residents in non-slum urban areas are unambiguously better off than slum dwellers. This finding implies that there is justification for slums garnering a sizable portion of the allocation of water and sanitation programs. On the other hand, we found that the distribution of private goods (monthly per capita expenditure and per capita living area) in non-slum areas does not dominate the distribution of these goods in the slums. In fact, at very low levels of MPCE and per capita living area, the distribution of these private goods in slums dominates the distribution in nonslums. This important finding implies that non-slum residents are not unequivocally better off than slum residents. Since slums are on an average poorer than other urban areas, it may be more pragmatic, therefore, to target policies at slum development. However, such policies would fail to reach the poorest residents of non-slum areas in both large and small cities. Our results make the case for a more inclusive policy that targets these groups as well.
\end{abstract}


It is estimated that by 2030, less developed regions will account for nearly 80 percent of the world's urban population (United Nations Population Division 2008). The surge in urban population in developing countries has accompanied the well-documented urbanization of poverty (Ravallion, Chen, and Sangraula 2007). The evidence of deterioration in urban areas extends to nonincome dimensions of poverty-for instance, the declining health status of children (Haddad, Ruel, and Garrett 1999).

Despite the increase in urban poverty and the growth of slums, adequate attention has not been paid to the welfare of urban households. This paper focuses on income and nonincome dimensions of intracity differences in well-being: namely, monthly per capita expenditure (MPCE), per capita area of household dwelling, and access to water and sanitation. Since simple averages such as the head count ratio or the proportion with access to water and sanitation fail to take into account the heterogeneity in urban areas, we compare the univariate and joint distributions of these dimensions across households living in slums and non-slum urban areas. We seek to determine whether households living in non-slum urban areas are unequivocally better off than those living in slums.

Urban poverty merits attention in its own right since it presents some issues distinct from those addressed in the typical analysis of poverty (Baker and Schuler 2004). There are three distinctive characteristics along which urban poverty and vulnerability differ from rural poverty: commoditization, environmental hazard, and social fragmentation (Moser, Gatehouse, and Garcia 1996). Urban households have to pay cash for all their necessities and are not able to rely on their production, in particular food. Security of tenure in urban areas is a greater problem than in rural areas. Commuting costs to work may also be higher in urban areas. These various aspects of urban life are referred to as commoditization. The risks from environmental hazards are also higher in urban areas. The combination of inadequate access to water and sanitation, poor quality housing, and overcrowding increases the health risks facing urban residents and the urban poor in particular. Slum dwellers are more disadvantaged in terms of maternal health services compared to households residing in non-slum urban areas (Rutstein, Johnson, and Montana 2005). The study undertaken by the Panel on Urban Population Dynamics concluded that poor households, particularly those located in slums, are unable to reap the urban "health dividend" (Montgomery, Stren, Cohen, and Reed 2003). Finally, urban areas exhibit social fragmentation. Hence, community-based mechanisms for sharing risk are less likely to exist in urban areas.

The literature on urban poverty mainly relied on univariate measures of income and nonincome dimensions of poverty. Despite evidence suggesting the heterogeneity of living standards within a city, rigorous examination of intracity differences in well-being is lacking. Evidence suggests that large differences exist among the urban poor in modes of livelihood and access to resources (Moser, Gatehouse, and Garcia 1996). Contrary to popular perception, not all slum dwellers are poor. A survey of nine slums in Howrah in the state of West Bengal revealed that almost two-thirds of the population living in the slums was above the poverty line (Sengupta 1999).

Lack of appropriate data has constrained rigorous analysis of intracity differences. A survey of housing conditions conducted by the National Sample Survey Organisation 
(NSSO) in 2002 is unusual in that, unlike standard surveys which provide information on rural and urban households, it identifies whether a household lives in urban slums or nonslum urban areas. Using this data we highlight differences in living standards across urban households. Since an examination of univariate distributions ignores possible correlations between different dimensions of urban poverty, we analyze the joint distribution of various indicators of well-being. We focus on multiple dimensions of deprivation by comparing the joint distribution of access to water, sanitation, MPCE, and per capita area of household dwelling across slums and non-slums.

Our use of distributional analysis has strong welfare theoretic underpinnings. In particular, we use the equivalence between welfare analysis and stochastic dominance first established by Atkinson and Bourguignon (1982) and extended to more than two dimensions by others (Fleurbaey, Hagneré, and Trannoy 2003; Gravel and Moyes 2006). An improved understanding of the multiple dimensions of urban poverty in India is relevant for the following reasons. India accounted for 10.4 percent of the world's urban population in 2007 (United Nations Population Division 2008), and the country is no exception to the ongoing urbanization of poverty. In the period 1983-2004, the number of Indians in rural areas living below the poverty line declined by 12.3 percent ( 31.03 million), while the total number of urban poor increased by 13.9 percent ( 9.86 million) (Government of India 2002, 2007).

\section{Distributional Analysis of The Dimensions of Poverty}

Households are deprived along both income and nonincome dimensions. The focus of the first Millennium Development Goal (MDG) is to halve the proportion of people living on less than a dollar a day by 2015. Other MDGs focus on nonincome dimensions of well-being: education, health, and access to water and sanitation (UN Millennium Project 2005). The literature on pro-poor growth has focused primarily on the income dimension. The logical question is whether the poor would benefit more than the nonpoor from improvements in nonincome dimensions. The paper by Grosse, Harttgen, and Klasen (2005) is notable for its attempt to empirically address the issue of pro-poor growth using three nonincome indicators: education, health, and nutrition.

Distribution analysis is one of the approaches that have been used to empirically address the various dimensions of poverty. Tarozzi and Mahajan (2007) analyze changes in nutritional status of boys and girls using two rounds of India's National Family Health Survey. They compare the cumulative distribution functions of height-for-age z-scores (reflecting long-term nutritional status) between boys and girls using one wave and also compare the cumulative distribution functions over time for boys and girls separately. They find that nutritional outcomes improved more for boys than for girls.

Such analyses, examining univariate distributions, ignore the fact that the different dimensions of well-being could be correlated. This recognition has led to an empirical literature focusing on joint distribution of various attributes. Kakwani and Silber (2008) provide a comprehensive overview of the issues concerning the measurement of multiple dimensions of poverty. The rationale for examining joint 
distributions can be better understood by considering the scenario examined by Duclos, Sahn, and Younger (2006). They focus on the joint distribution of per capita household expenditure and the height-for-age z-scores of children across rural and urban areas, using data from Ghana, Madagascar, and Uganda. Their comparison of the univariate distribution of income suggests that the outcomes in urban areas are superior to those in rural areas. However, when they consider the joint distribution of income and health outcomes, they find that urban outcomes are not unequivocally superior to rural outcomes.

Distributional methods are ideal for analyzing the various dimensions of urban poverty. Examining joint distributions in the urban context makes sense for the following reason. A household might not be poor along the income dimension but might suffer from inadequate access to water since it may not be adequately provided by municipal authorities in some urban areas. Alternatively, a household might be poor along the income dimension, yet have adequate access to water and sanitation. Compared to persons living in non-slum urban areas, slum dwellers are more likely to be deprived in terms of access to water and sanitation (NSSO 2003). Given the income heterogeneity in slums, there is no reason to believe that access to water and sanitation will be correlated with income. The NSSO data provide an ideal means of examining the joint distributions across slums and non-slum urban areas.

In the literature, spatial comparisons of the joint distributions across rural and urban areas have been undertaken. However, such comparisons have not been undertaken across households living in slums and non-slum urban areas. In the developing countries, the population residing in slums has increased in line with the higher level of urbanization. It is estimated that a sixth of the world's population lives in slum-like conditions. South Asia has the largest share of slum dwellers, with 56 percent of the population living under slum conditions (United Nations Population Fund 2007). Consequently, MDG-7 (Target 11) aims at improving the lives of at least 100 million slum dwellers by 2020 .

\section{DATA}

We use a data set collected by NSSO in 2002 covering 41,916 urban households. The survey identified 6,138 slum households and squatters, 35,703 households from nonslum urban areas, and 75 households without a house. (For details on the sampling frame and the methodology, see NSSO 2004.) Each household is assigned a sampling weight by NSSO, and we use these weights in our analysis.

UN-Habitat defines a slum household as a group of individuals living under the same roof in an urban area and lacking one or more of the following: durable housing, sufficient living space, easy access to safe water in sufficient amounts at an affordable price, access to adequate sanitation, and security of tenure that prevents forced evictions. The definition of a slum used by NSSO is similar to that of UN-Habitat (see NSSO 2003). The data distinguish two types of slums: notified and non-notified. In the case of 
notified slums a notification has been issued by the appropriate municipality, corporation, local body, or development authority, which leads to improved provision of public goods including water and sanitation.

Our focus is on individuals living in notified slums, non-notified slums, and nonslum urban areas. We ignore residents of squatter settlements and the homeless since we have very few observations on such households. We conduct our analysis at the all-India level because the number of observations on slum households would be greatly reduced by undertaking the analysis at the city level. We focus on 26 major states of India

In line with the literature on poverty measurement, our unit of analysis is the individual. We ascribe to each individual the MPCE of the household to which he or she belongs. ${ }^{1}$ We smooth the MPCE variable as follows. We have 122 MPCE classes starting with Rs 0-50 and increasing in increments of Rs 50. Each individual is assigned the midpoint consumption of his or her class. As a measure of sufficient living space, we use per capita floor area (the sum of the area of living room, other rooms, covered veranda, and uncovered veranda divided by the household size-measured in square feet). With regard to availability of public goods, we consider the drainage facilities available to the household and hence to the individual (no drainage, open kutcha, open pucca, ${ }^{2}$ covered pucca, and underground), the drinking water facility (community use, use restricted to households in the building, and household's exclusive use). An individual's right to the drinking water facility identifies both access and availability. Our choice of variables is driven by the definition of slums proposed by UN-Habitat. ${ }^{3}$

\section{DESCRIPTIVE ANALYSIS}

First, we consider the distribution of private goods. We plot the distribution of MPCE for each of the three locations: notified slums, non-notified slums, and non-slum urban areas (Figure 1). Figure 1a indicates that the distribution of MPCE in non-slum urban areas overlaps the distribution of MPCE in notified slums and non-notified slum at the bottom end of the distribution. It is apparent that the gap between individuals living in non-slum urban areas and residents of both types of slum areas increases as the rank of individuals in the MPCE distribution increases.

We also plot the distribution of per capita dwelling area for each of the three locations after arranging individuals in ascending order of their rank in the distribution. At the bottom end of the distribution of per capita area, plotted in Figure 2, the three curves overlap one another. It is not surprising that the distribution of per capita area is similar to that of MPCE since both are private goods and thus positively correlated.

A household's access to water and sanitation is determined not only by its location but also by its economic circumstances. Thus access to such services could vary across households from different MPCE classes because no city provides universal coverage. We find differences in access to sanitation facilities across notified and nonnotified slums. In 2002, 25 percent of notified slums had underground or covered drainage, compared to 13 percent of non-notified slums. At the other end of the spectrum, 
15 percent of slums and 44 percent of non-notified slums lacked a drainage system (NSSO 2003).

Table 1 demonstrates that, irrespective of the place of residence, the proportion of households without drainage decreases as we move from households in the lowest (Rs 0300) MPCE class to the highest (over Rs 1925) class. Similarly, Table 2 shows that the proportion of households with access to water from a community source decreases as we move from households in the lowest to the highest MPCE class. This implies a positive correlation between access to improved water and sanitation and MPCE. It also true, however, that every MPCE class contains households with access to each type of drainage system and with access to each type of water source.

The insights gleaned from Tables 1 and 2 are sharpened by plotting the conditional distributions for the three urban locations. For each location, we plot the distribution of MPCE for each type of drainage (Figures 3-5). Similarly, for each location, we plot the distribution of MPCE for each type of access rights to water source (Figures 6-8).

For strictly illustrative purposes, we define individuals as poor if their MPCE is below Rs 496, the estimated all-India urban poverty line for 2002. For each type of drainage and rights to water source, a significant proportion of individuals live below the poverty line. From Figure 3 one can infer the correlation between MPCE and drainage in the non-slum urban areas. The cumulative density function of MPCE of individuals with underground drainage (the best drainage option) clearly dominates that of individuals without such access. However, this is not true for individuals living in notified and nonnotified slums (Figures 4-5).

Similarly, from Figure 6 it is evident that the cumulative density function of MPCE of individuals with exclusive rights to water source clearly dominates that of individuals living without such access. Again, this is not true for individuals living in notified and non-notified slums (Figures 7-8).

The preceding findings reflect the importance of analyzing not only income and consumption levels but also access to water and sanitation services for households across the different income or consumption classes.

\section{EMPIRICAL METHODS}

We now turn to the empirical methods used in this paper. To compare the joint distribution of a set of $\mathrm{K}$ goods across individuals living in slum and non-slum urban areas, ${ }^{4}$ we test whether the distribution in the non-slum areas $\left(F^{A}().\right)$ dominates the distribution in the slums $\left(F^{B}().\right)$. In the theoretical literature, the equivalence between welfare analysis and stochastic dominance has been well established. The robust criteria used for welfare analysis are generalizations, to more than two attributes, of the first- and second-order stochastic dominance criteria of Atkinson and Bourguignon (1982). These are known to correspond to the unanimity of results of utilitarian welfare evaluations taken over a specific class of individual utility functions. 
We use the Union-Intersection method ${ }^{5}$ to test for stochastic dominance of $F^{A}$ over $F^{B}$ (Bishop and Formby 1999).

Let $\hat{F^{A}, F^{B}}$ be the empirical distributions. We calculate $T_{i}=\frac{\hat{F^{A}\left(t_{i}\right)-F^{B}\left(t_{i}\right)}}{V\left(F^{A}\left(t_{i}\right)-F^{B}\left(t_{i}\right)\right)}$,

for all $t_{i}$ in the $\mathrm{K}$ dimensional grid (over all values of the $\mathrm{K}$ goods observed in the data),

and the variance $\hat{V}$ is the variance estimator derived by Davidson and Duclos (2000).

Then $F^{A}$ dominates $F^{B}$ iff $\min \left(T_{1}, \ldots, T_{\mathrm{k}}\right)<-C_{\alpha}$ and $\max \left(T_{1}, \ldots, T_{\mathrm{k}}\right) \leq C_{\alpha}$, where $C_{\alpha}$ is the critical value (at significance level $\alpha$ ) given by the Studentized Modulos Distribution.

A necessary condition for $F^{A}($.$) to dominate F^{B}($.) when we consider $\mathrm{K}$ attributes is that no region in the marginal distribution of $A$ must be dominated by the marginal distribution of $B$ for each of the $\mathrm{K}$ attributes.

\section{RESULTS}

The results of the pairwise comparisons are reported in Table 3 . When we compare the univariate distributions of MPCE or per capita area for non-slum urban with each type of slum, the minimum value of $T_{i}$ is lower than $-C_{\alpha}$ but the maximum value of $T_{i}$ is greater than $C_{\alpha}$ (Table 3 ). This implies that neither distribution in non-slums dominates the corresponding distribution in either type of slum. In fact, at very low values of these variables, the univariate distribution of MPCE and per capita area in notified and non-notified slums dominates the corresponding distribution in non-slum urban areas. The domination at the lower end of the distribution implies that the joint distribution of MPCE, per capita area, drainage, and rights to water source for individuals living in non-slum urban areas cannot dominate those for individuals living in either type of slum as this violates the necessary condition for dominance.

The significance of these findings can be gauged by the fact that if one used a fixed poverty line for the year 2002, the only conclusion one can derive is that the head count ratio is lower at 20.66 percent in the non-slums compared to 34.23 percent in the notified slums and 40.62 percent in the non-notified slums. The presence of individuals living well below the poverty line in non-slum urban areas, a fact that gets shrouded by looking solely at the head count ratio, leads to the nondominance result. In similar vein, although the average per capita area of dwellings is higher (131.61 sq meters) in nonslum areas than in either the notified slums (70.15 sq meters) or the non-notified slums (67.44 sq meters), distribution of per capita area in non-slum areas does not dominate distribution in either notified or non-notified slums.

The joint distribution of drainage facilities and rights to water source in non-slum urban areas dominates the corresponding distributions in notified and non-notified slums. This corroborates the observation that the provision of water and sanitation services lags in the slums. Our findings imply the need for a concerted effort to improve such amenities as part of slum development and upgrading programs. 
We accept the hypothesis that the univariate distribution of MPCE and per capita area of dwelling in notified slums dominates the distribution in non-notified slums. Further, the joint distribution of drainage facilities and rights to water source in notified slums dominates the corresponding distributions in non-notified slums. This result can be explained by the fact that the act of notification leads to a greater share of funds within development programs going to the notified slums, thereby improving living conditions. Further, we find that the joint distribution of consumption of public and private goodsnamely, MPCE, per capita area, drainage, and rights to water source - of individuals living in notified slums dominates the corresponding distribution in non-notified slums. This result implies that individuals living in notified slums are unequivocally better off than dwellers in non-notified slums.

MPCE and per capita area are correlated since both reflect household standard of living. The finding that the distribution of per capita area in non-slum urban areas does not dominate the distribution in urban slums substantiates our results pertaining to the distribution of MPCE.

A final question is whether the poorest individuals in non-slum areas live predominantly in smaller cities. This is indeed true. However, among those individuals with an MPCE less than Rs 125, a non-negligible 22 percent live in cities with a population above one million. Thus, the non-slum urban poor are dispersed across cities of vastly different sizes.

\section{CONCLUSION}

In the face of inadequate government investments in urban infrastructure, there is a downside to urbanization. Higher levels of urbanization have gone hand in hand with the growth of slums. It is often argued that since slums are visual manifestations of poverty, slum dwellers are unequivocally worse off than non-slum dwellers. We addressed this issue empirically through a welfare theoretic approach. We considered two public goods - type of drainage and rights to water source-as well as two private goods-MPCE and per capita area of dwelling. An examination of the univariate distribution of these goods would ignore any possible correlations. Hence we also examined the joint distribution of these goods and compared the outcomes in slums and non-slum urban areas of India.

We first established that if utility is defined as access to public goods such as water and sanitation, then residents in non-slum urban areas are unambiguously better off than slum dwellers. This finding implies that there is justification for slums garnering a sizable portion of the allocation of water and sanitation programs. On the other hand, we found that the distribution of private goods (MPCE and per capita living area) in nonslum areas does not dominate the distribution of these goods in the slums. In fact, at very low levels of MPCE and per capita living area, the distribution of these private goods in slums dominates the distribution in non-slums. This important finding implies that nonslum residents are not unequivocally better off than slum residents. It also suggests that

the poorest non-slum residents are worse off than the poorest slum dwellers. It may be 
more pragmatic, therefore, to target policies at slum development, since slums are on average poorer than other urban areas. However, such policies would fail to reach the poorest residents of non-slum areas in both large and small cities. Our results make the case for a more inclusive policy that targets these groups as well.

\section{NOTES}

1 Because the data do not provide information on the composition of households, we are unable to adjust the consumption expenditure of households using adultequivalence scales. This is not a limitation, however, since poverty estimates in India are generated after dividing the household's expenditure by household size rather than by adult-equivalent-adjusted household size.

2 Kutcha implies a non-concrete structure, and pucca implies a more permanent concrete structure.

3 Owing to data limitations, we are unable to incorporate the following dimensions in our analysis: durable housing, price of water, type of latrine, and security of tenure.

4 In this approach we undertake pairwise comparisons of notified slums, nonnotified slums, and non-slum urban areas.

5 We do not use the Intersection-Union method as these tests have low power.

\section{REFERENCES}

Atkinson, A. B. and F. Bourguignon. 1982. "The comparison of multi-dimensioned distribution of economic status," Review of Economic Studies 49: 183-201.

Baker, J. and N. Schuler. 2004. "Analyzing urban poverty: A summary of methods and approaches," World Bank Policy Research Working Paper 3399.

Bishop, J. A. and J. P. Formby. 1999. "Tests of significance for Lorenz partial orders," in J. Silber (ed.), Handbook of Income Inequality Measurement. London: Kluwer Academic Press, pp. 315-339.

Davidson, R. and J.-Y. Duclos. 2000. "Statistical inference for stochastic dominance and for the measurement of poverty and inequality," Econometrica 68(6):1435-1465.

Duclos, P. Y., D. Sahn, and S. D. Younger. 2006. "Robust multidimensional spatial poverty comparisons in Ghana, Madagascar, and Uganda," World Bank Economic Review 20(1): 91-113. 
Fleurbaey, M., C. Hagneré, and A. Trannoy. 2003. "Welfare comparisons with bounded equivalence scales,” Journal of Economic Theory 110: 309-336.

Government of India. 2002. National Human Development Report 2001, Planning Commission, Government of India, March.

- 2007. Poverty Estimates for 2004-05, Planning Commission, Government of India, March. Accessed: <<http://www.planningcommission.gov.in/news/ prmar07.pdf >>.

Gravel, N. and P. Moyes. 2006. "Ethically robust comparisons of distributions of two attributes," IDEP working paper, no. 06-04.

Grosse, M., K. Harttgen, and S. Klasen. 2005. "Measuring pro-poor growth with nonincome indicators," Ibero-America Institute for Economic Research.

Haddad, L., M. T. Ruel, and J. L. Garrett. 1999. "Are urban poverty and undernutrition growing? Some newly assembled evidence," World Development 27(11): 18911904.

Kakwani, N. and J. Silber. 2008. Quantitative Approaches to Multidimensional Poverty Measurement. Palgrave Macmillan.

Montgomery, M., R. Stren, B. Cohen, and H. Reed (eds.). 2003. Cities Transformed: Demographic Change and Its Implications in the Developing World. Washington, DC: National Academy Press.

Moser, C., M. Gatehouse, and H. Garcia. 1996. "Urban poverty research sourcebook module II: Indicators of urban poverty," UNDP/UNCHS (Habitat)/World Bank, Working Paper No 5, September.

National Sample Survey Organisation. 2003. "Condition of urban slums," Report No. 486, Ministry of Statistics and Programme Implementation, Government of India.

- 2004. "Housing condition in India: Housing stock and constructions," Report No. 488, Ministry of Statistics and Programme Implementation, Government of India.

Ravallion, M., S. Chen, and P. Sangraula. 2007. "New evidence on the urbanization of global poverty," Population and Development Review 33(4): 667-701.

Rutstein, S., K. Johnson, and L. Montana. 2005. "Targeting health services to the urban poor: Is slum geography enough?” paper presented at International Union for the Scientific Study of Population, XXV International Population Conference, Tours, France, July. 
Sengupta, C. 1999. "Dynamics of community environmental management in Howrah slums," Economic and Political Weekly, 22 May, pp. 1290-1296.

Tarozzi, A. and A. Mahajan. 2007. "Child nutrition in India in the nineties," Economic Development and Cultural Change 55(3): 441-486.

UN Millennium Project. 2005. Investing in Development: A Practical Plan to Achieve the Millennium Development Goals, Report to the UN Secretary-General. London and Sterling, VA: Earthscan.

United Nations Population Division. 2008. "An overview of urbanization, internal migration, population distribution and development in the world," Expert Group Meeting on Urbanization, Internal Migration, Population Distribution and Development, New York, January. Accessed: <<http://www.un.org/esa/popul ation/meetings/EGM_PopDist/Bravo.pdf >>.

United Nations Population Fund. 2007. State of World Population 2007: Unleashing the Potential of Urban Growth. New York: United Nations Population Fund. 
Figure 1: Distribution of Households by Monthly Per Capita Expenditure (Rs)

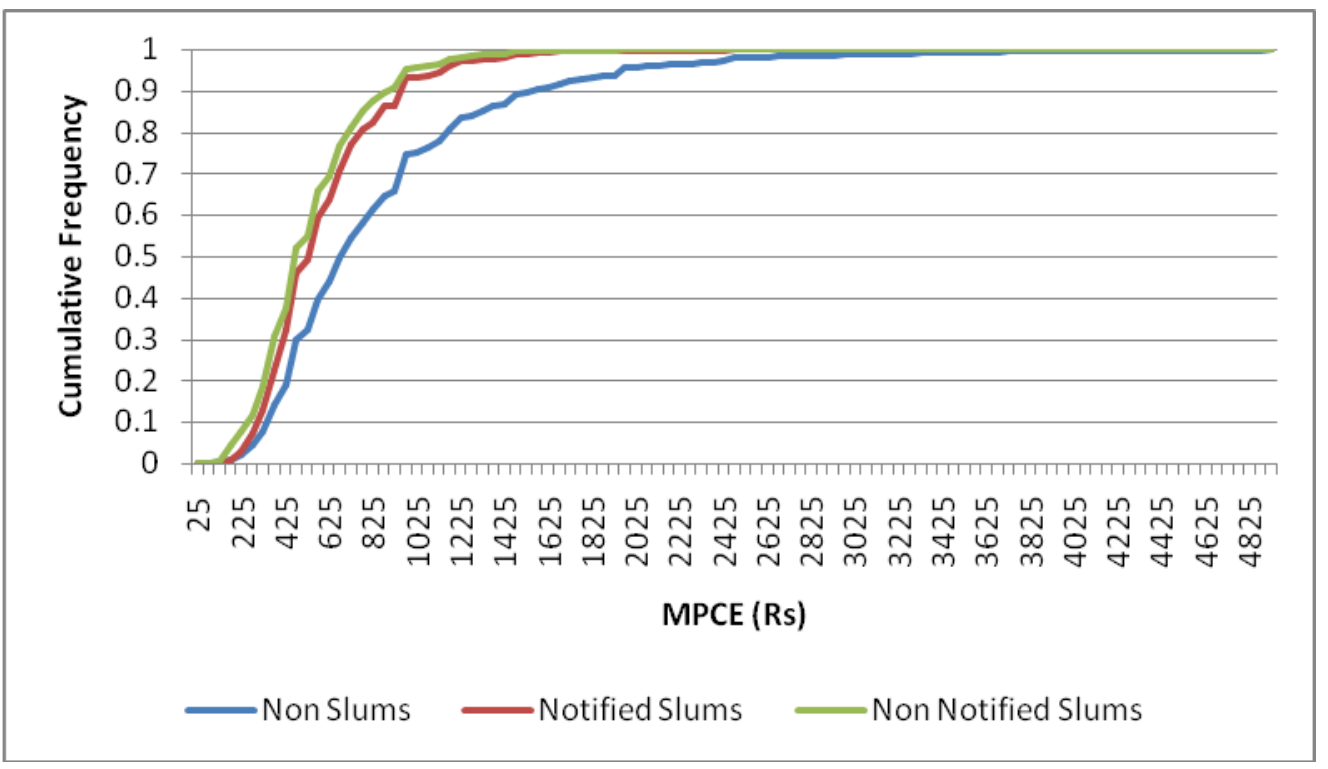

Figure 1a: Distribution of Monthly Per Capita Expenditure (Rs) at Low Levels of Monthly Per Capita Expenditure

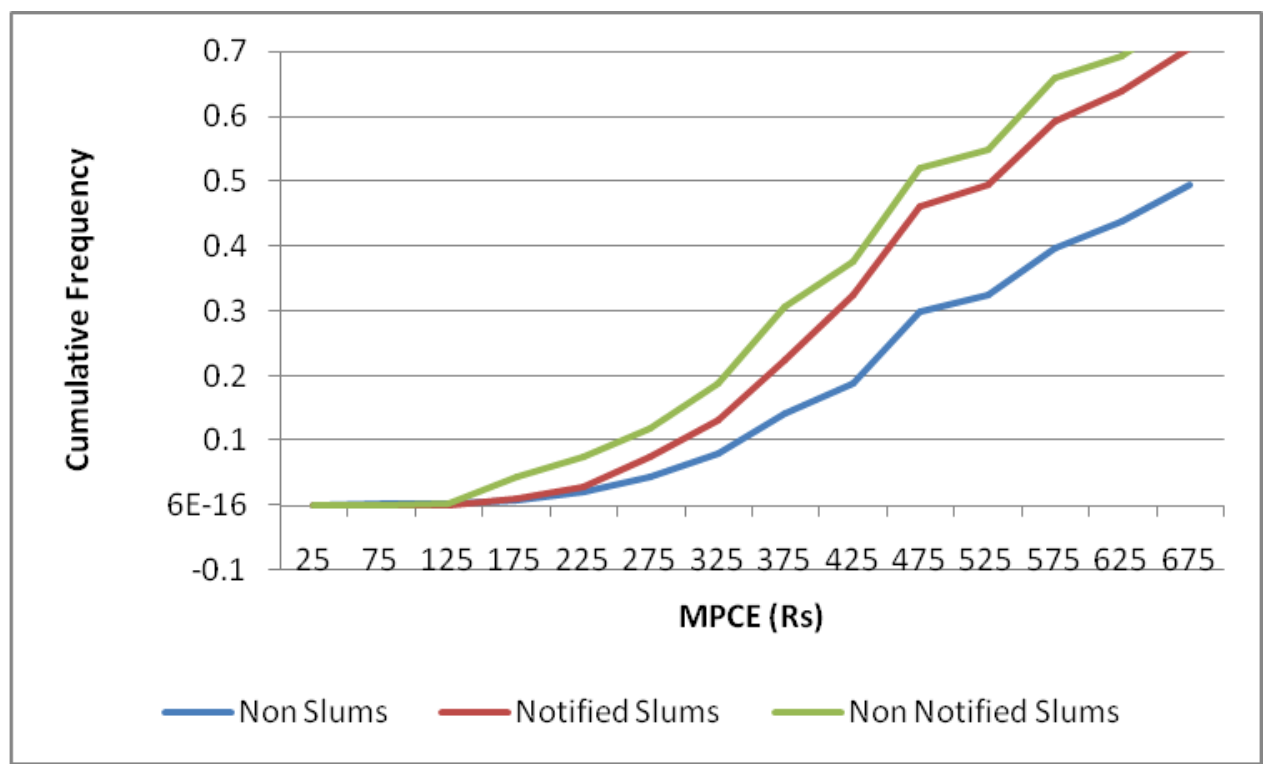


Figure 2: Distribution of Per Capita Area (Square Feet) at Low Levels of Per Capita Area

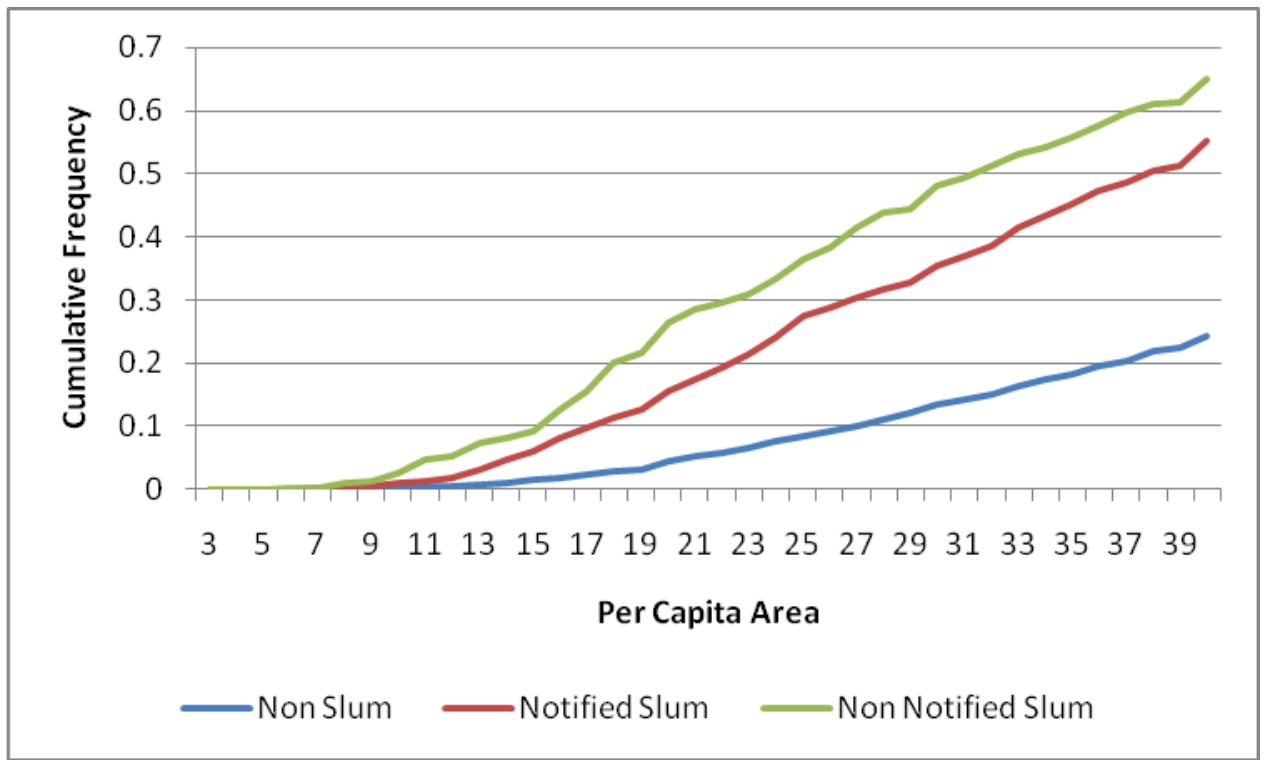


Figure 3: Distribution of Monthly Per Capita Expenditure (MPCE) by Drainage Type in Non-Slum Urban Areas

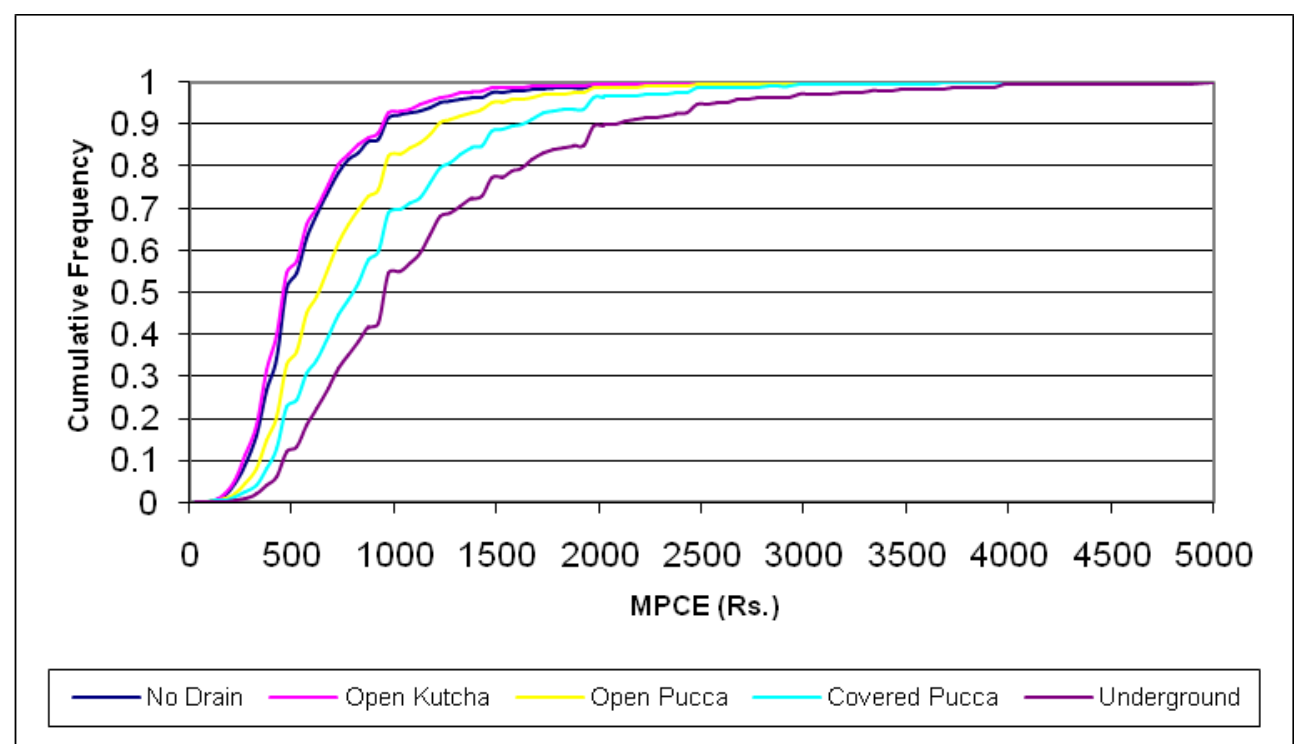


Figure 4: Distribution of Monthly Per Capita Expenditure (MPCE) by Drainage Type in Notified Slums

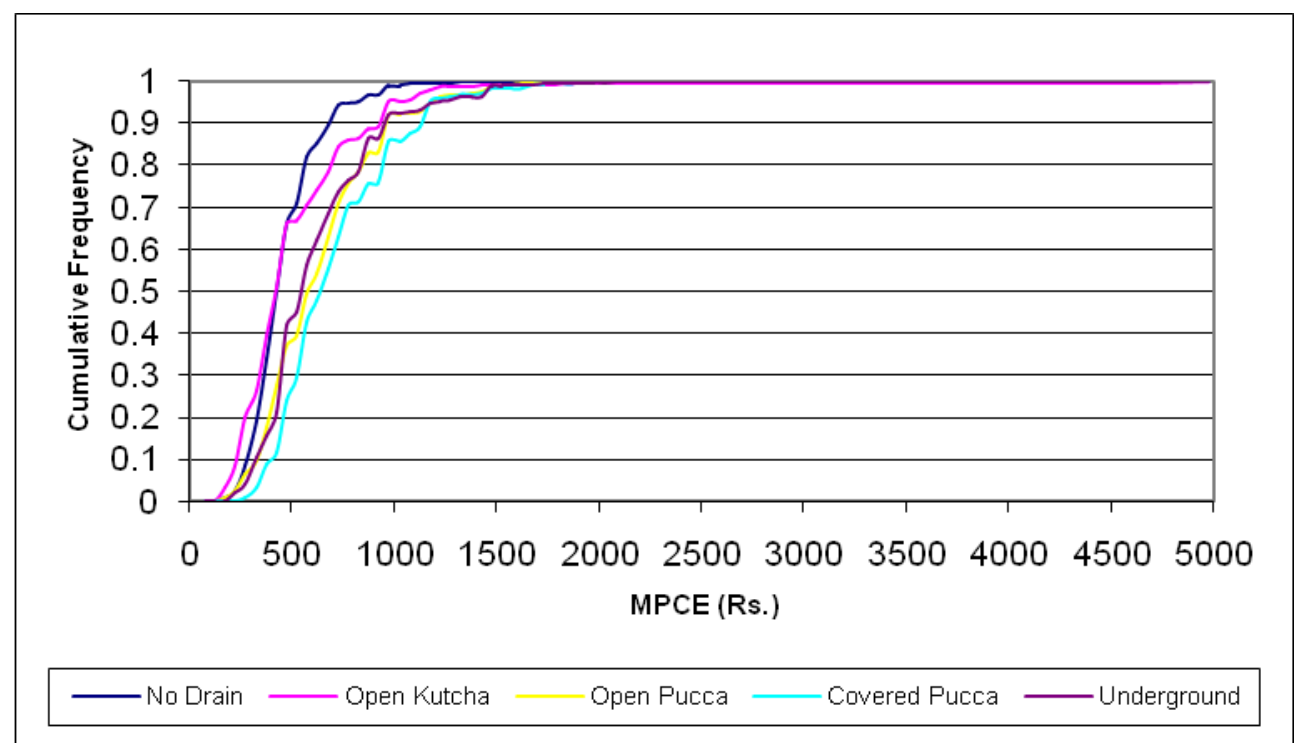


Figure 5: Distribution of Monthly Per Capita Expenditure (MPCE) by Drainage Type in Non-Notified Slums

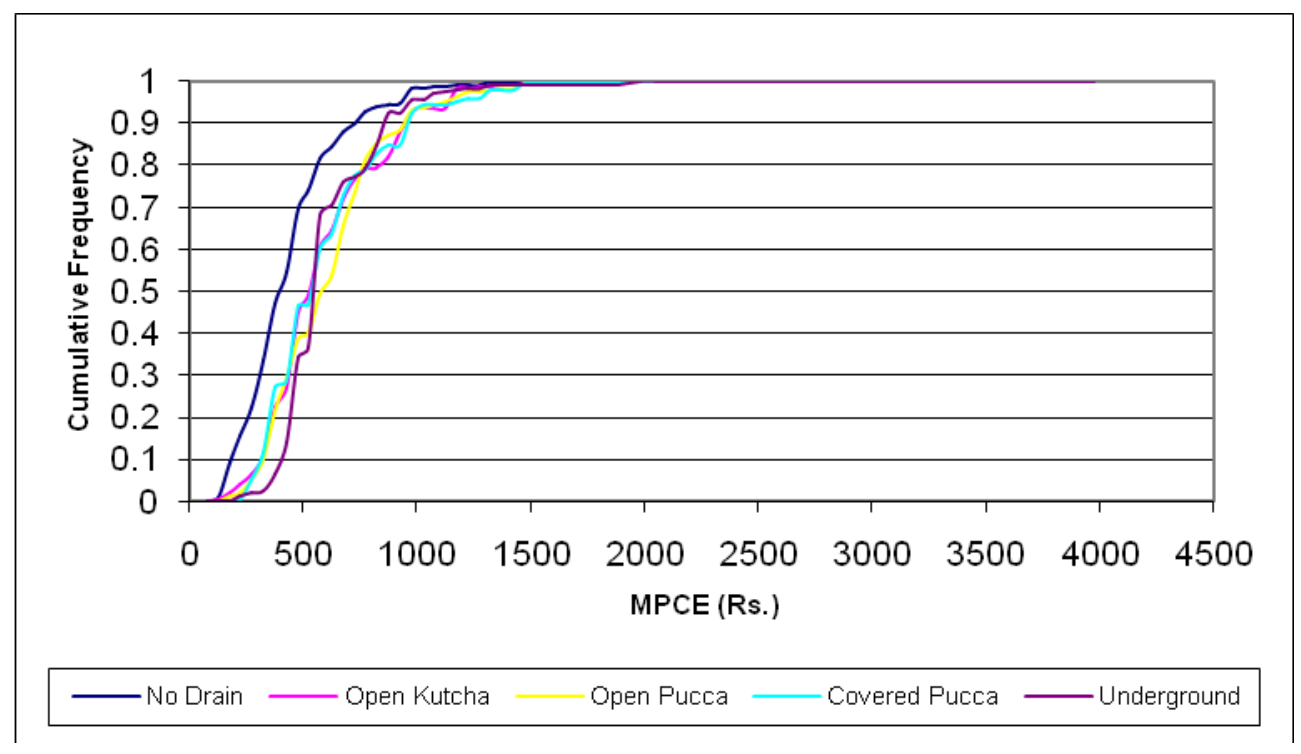


Figure 6: Distribution of Monthly Per Capita Expenditure (MPCE) by Rights to Water Source in Non-Slum Urban Areas

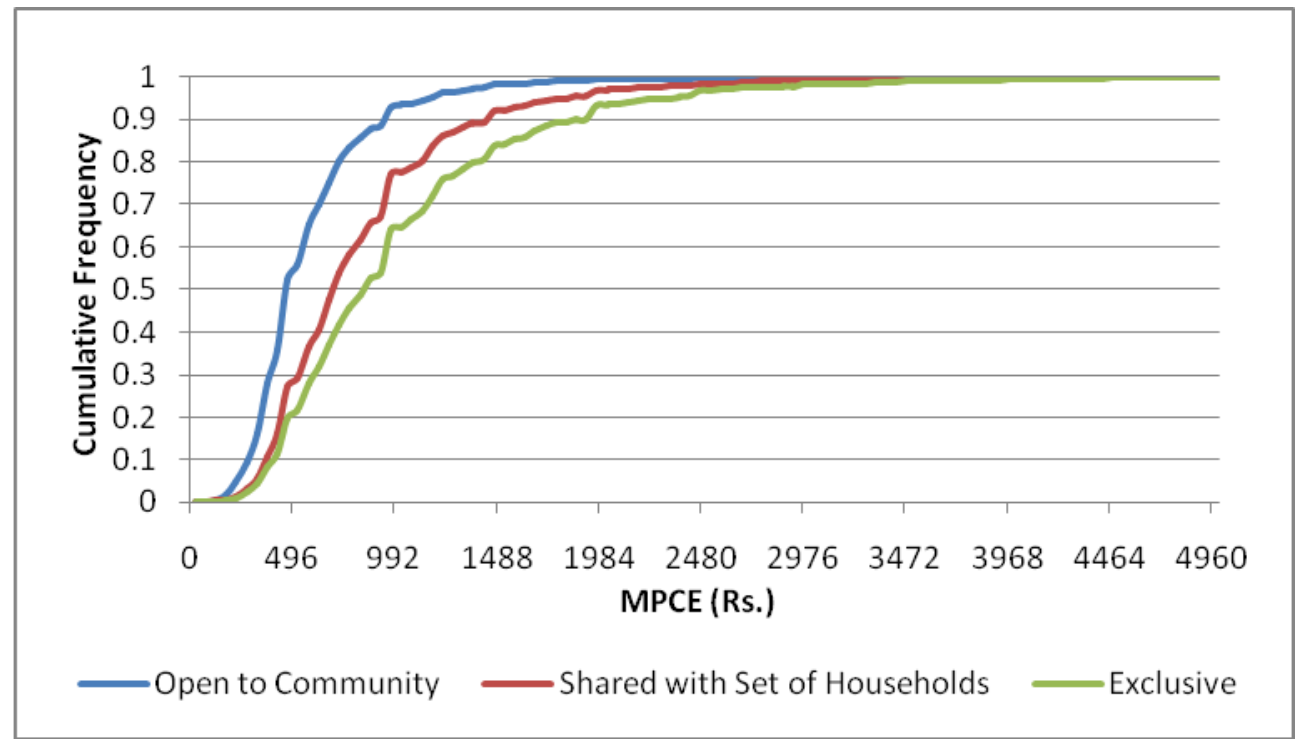


Figure 7: Distribution of Monthly Per Capita Expenditure (MPCE) by Rights to Water Source in Notified Slums

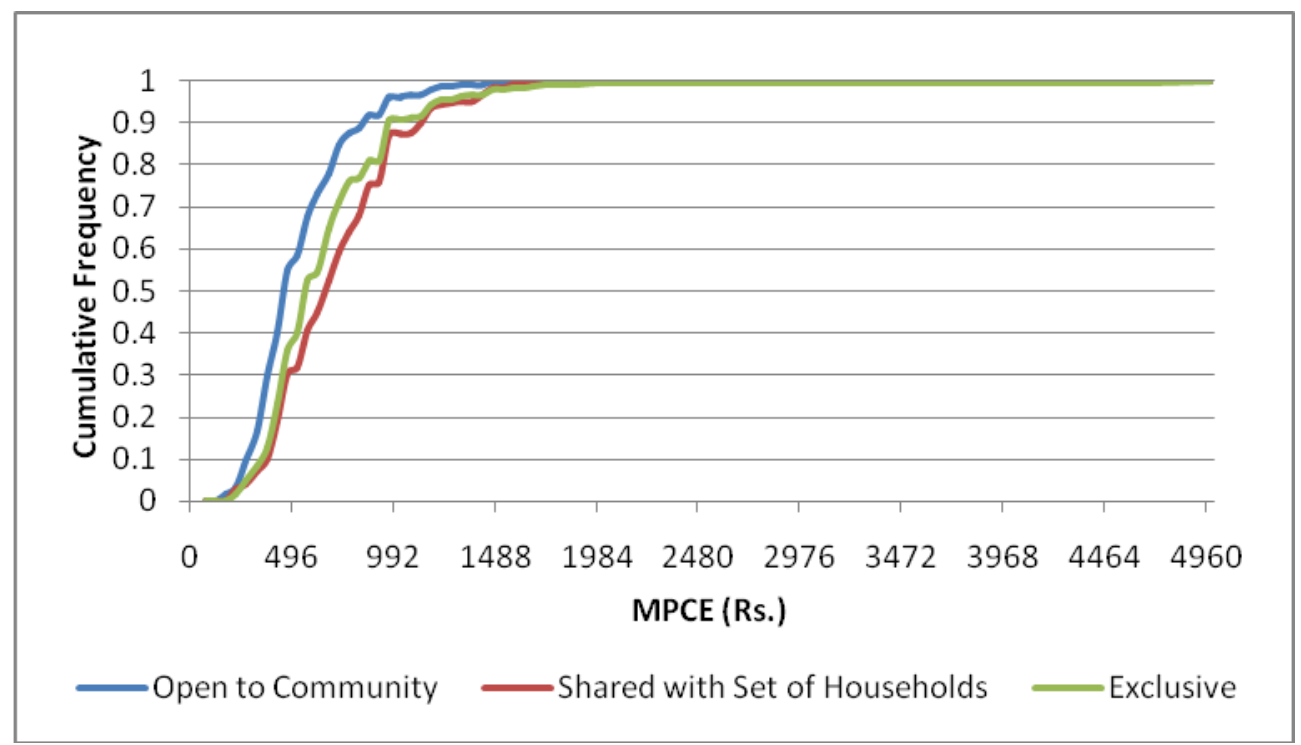


Figure 8: Distribution of Monthly Per Capita Expenditure (MPCE) by Rights to Water Source in Non-Notified Slums

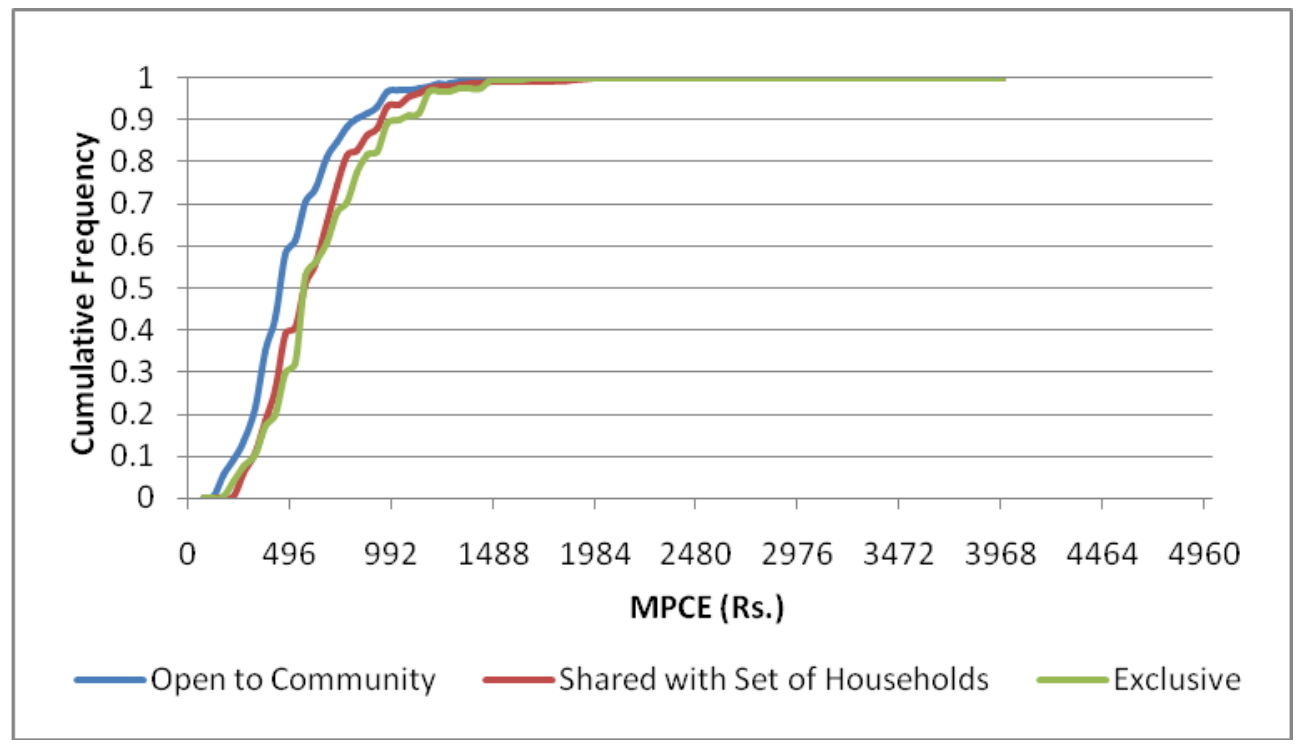


Table 1: Distribution of Households by Type of Drainage Arrangement for each

Monthly Per Capita Expenditure Class

\begin{tabular}{|c|c|c|c|c|c|c|}
\hline $\begin{array}{l}\text { MPCE } \\
\text { (Rs) }\end{array}$ & Residing in & $\begin{array}{c}\text { No } \\
\text { Drain }\end{array}$ & $\begin{array}{l}\text { Open } \\
\text { Kutcha }\end{array}$ & $\begin{array}{l}\text { Open } \\
\text { Pucca }\end{array}$ & $\begin{array}{c}\text { Covered } \\
\text { Pucca }\end{array}$ & Underground \\
\hline \multirow{2}{*}{$0-300$} & Slum \& Squatter Settlement & 48.5 & 24.7 & 21.5 & 0.6 & 4.7 \\
\hline & Other Area & 34 & 21.8 & 26.7 & 9.3 & 8.2 \\
\hline \multirow{2}{*}{$300-350$} & Slum \& Squatter Settlement & 57.1 & 13.9 & 18.1 & 4.1 & 6.7 \\
\hline & Other Area & 38.2 & 17.2 & 31.5 & 5.6 & 7.5 \\
\hline \multirow{2}{*}{$350-425$} & Slum \& Squatter Settlement & 39 & 16.7 & 30.5 & 7.3 & 6.4 \\
\hline & Other Area & 32.7 & 16.3 & 33.6 & 7.4 & 10 \\
\hline \multirow{2}{*}{$425-500$} & Slum \& Squatter Settlement & 39.4 & 18.1 & 28.3 & 5.5 & 8.7 \\
\hline & Other Area & 31.5 & 14.9 & 30.7 & 10.3 & 12.6 \\
\hline \multirow{2}{*}{$500-575$} & Slum \& Squatter Settlement & 34.7 & 10.4 & 26.3 & 10.6 & 17.9 \\
\hline & Other Area & 26.9 & 11 & 34.7 & 10.4 & 17 \\
\hline \multirow{2}{*}{$575-665$} & Slum \& Squatter Settlement & 25.2 & 10.5 & 36.2 & 10.9 & 17.1 \\
\hline & Other Area & 25 & 9 & 36.6 & 8.9 & 20.6 \\
\hline \multirow{2}{*}{$665-775$} & Slum \& Squatter Settlement & 20 & 12.4 & 47.4 & 10.2 & 10.1 \\
\hline & Other Area & 16.9 & 9.5 & 38 & 12.1 & 23.5 \\
\hline \multirow{2}{*}{$775-915$} & Slum \& Squatter Settlement & 14 & 7.1 & 49.9 & 10.8 & 18.2 \\
\hline & Other Area & 16.1 & 6.7 & 34.6 & 15.6 & 26.9 \\
\hline \multirow{2}{*}{$915-1120$} & Slum \& Squatter Settlement & 15.3 & 14.1 & 39.9 & 16.7 & 14 \\
\hline & Other Area & 11.9 & 6.1 & 32.2 & 14.1 & 35.7 \\
\hline $1120-$ & Slum \& Squatter Settlement & 7.1 & 11.8 & 45.1 & 23.1 & 12.9 \\
\hline 1500 & Other Area & 6.9 & 4.1 & 29.3 & 17.4 & 42.2 \\
\hline $1500-$ & Slum \& Squatter Settlement & 4.9 & 5.1 & 50.3 & 18.4 & 21.4 \\
\hline 1925 & Other Area & 6.8 & 2.4 & 23.4 & 16.4 & 50.8 \\
\hline Over & Slum \& Squatter Settlement & 2.7 & 7.6 & 32.6 & 22 & 35 \\
\hline 1925 & Other Area & 3.9 & 1.4 & 13.4 & 13.3 & 68 \\
\hline All & Slum \& Squatter Settlement & 27.8 & 12.8 & 35.7 & 10.7 & 13 \\
\hline Classes & Other Area & 17.4 & 8 & 30.8 & 12.7 & 31.1 \\
\hline
\end{tabular}




\begin{tabular}{|c|c|c|c|c|}
\hline MPCE (Rs) & Residing in & Community Use & Restricted Use & Exclusive Use \\
\hline \multirow{2}{*}{$0-300$} & Slum \& Squatter Settlement & 84.1 & 5.6 & 10.3 \\
\hline & Other Area & 54.8 & 21.1 & 24.1 \\
\hline \multirow{2}{*}{$300-350$} & Slum \& Squatter Settlement & 84.7 & 6.9 & 8.4 \\
\hline & Other Area & 56.1 & 19.1 & 24.8 \\
\hline \multirow{2}{*}{$350-425$} & Slum \& Squatter Settlement & 82.2 & 10.9 & 6.9 \\
\hline & Other Area & 54 & 20.6 & 25.5 \\
\hline \multirow{2}{*}{$425-500$} & Slum \& Squatter Settlement & 69.6 & 14.6 & 15.9 \\
\hline & Other Area & 47.7 & 23.7 & 28.7 \\
\hline \multirow{2}{*}{$500-575$} & Slum \& Squatter Settlement & 72.3 & 11 & 16.7 \\
\hline & Other Area & 42.1 & 22.8 & 35.1 \\
\hline \multirow{2}{*}{$575-665$} & Slum \& Squatter Settlement & 68.1 & 12.8 & 19.1 \\
\hline & Other Area & 38.5 & 23.8 & 37.7 \\
\hline \multirow{2}{*}{$665-775$} & Slum \& Squatter Settlement & 60.8 & 18.1 & 21.2 \\
\hline & Other Area & 28.3 & 29.8 & 41.9 \\
\hline \multirow{2}{*}{$775-915$} & Slum \& Squatter Settlement & 53.6 & 25.8 & 20.5 \\
\hline & Other Area & 25.2 & 30.4 & 44.3 \\
\hline \multirow{2}{*}{$915-1120$} & Slum \& Squatter Settlement & 51.6 & 26.1 & 22.2 \\
\hline & Other Area & 16.1 & 31 & 52.9 \\
\hline \multirow{2}{*}{$1120-1500$} & Slum \& Squatter Settlement & 39.7 & 37.2 & 23.1 \\
\hline & Other Area & 12.2 & 27.7 & 60 \\
\hline \multirow{2}{*}{$1500-1925$} & Slum \& Squatter Settlement & 35.2 & 35.1 & 29.7 \\
\hline & Other Area & 7.7 & 28.9 & 63.4 \\
\hline \multirow{2}{*}{ Over 1925} & Slum \& Squatter Settlement & 17 & 27.6 & 55.5 \\
\hline & Other Area & 4.6 & 22.9 & 72.5 \\
\hline \multirow{2}{*}{ All Classes } & Slum \& Squatter Settlement & 65 & 17.4 & 17.6 \\
\hline & Other Area & 26.8 & 26.3 & 46.9 \\
\hline
\end{tabular}


Table 3: Results of First Order Stochastic Dominance Tests

\begin{tabular}{|c|c|c|c|c|}
\hline Null Hypothesis & Minimum & Maximum & $\begin{array}{c}\text { Critical } \\
\text { Value } \\
\left(C_{\alpha}\right)\end{array}$ & Result \\
\hline \multicolumn{5}{|l|}{ Monthly Per Capita Expenditure } \\
\hline Non-Slum Urban Dominates Notified Slum & -90.11 & 15.64 & 3.93 & Reject \\
\hline Non-Slum Urban Dominates Non-notified Slum & -105.18 & 10.10 & 3.93 & Reject \\
\hline Notified Slum Dominates Non-notified Slum & -16.31 & -0.52 & 3.87 & Accept \\
\hline \multicolumn{5}{|l|}{ Per Capita Area of Dwelling } \\
\hline Non-Slum Urban Dominates Notified Slum & -98.28 & 5.49 & 4.35 & Reject \\
\hline Non-Slum Urban Dominates Non-notified Slum & -106.12 & 6.24 & 4.35 & Reject \\
\hline Notified Slum Dominates Non-notified Slum & -21.03 & 4.05 & 4.34 & Accept \\
\hline \multicolumn{5}{|l|}{ Drainage and Access to Water Source } \\
\hline Non-Slum Urban Dominates Notified Slum & -84.90 & -2.54 & 3.52 & Accept \\
\hline Non-Slum Urban Dominates Non-notified Slum & -107.81 & -2.54 & 3.52 & Accept \\
\hline Notified Slum Dominates Non-notified Slum & -38.46 & -16.67 & 3.52 & Accept \\
\hline \multicolumn{5}{|l|}{$\begin{array}{l}\text { MPCE, Per Capita Area of Dwelling, Drainage, } \\
\text { and Access to Water Source }\end{array}$} \\
\hline Notified Slum Dominates Non-notified Slum & -38.8 & 5.15 & 5.49 & Accept \\
\hline
\end{tabular}




\section{Poverty, Gender, and Youth Working Papers}

If still in print, single copies of up to three working papers from 1989 through 2003 are available free of charge.

Beginning with the 2004 issues, working papers are no longer available in print format. Instead they are distributed electronically. As each new paper is completed, subscribers are notified by e-mail and a link to the paper is provided.

To subscribe to the Poverty, Gender, and Youth working paper e-mail notification list, or to obtain back issues from 1989 to 2003, please send your request to pgywp@ popcouncil.org.

PDFs of recent issues are available at www.popcouncil.org/publications/wp/index.html

2008

11

S. Chandrasekhar and Abhiroop

Mukhopadhyay, "Multiple

dimensions of urban well-being:

Evidence from India"

10 Sajeda Amin and Luciana Suran, "Terms of marriage and time-use patterns of young wives: Evidence from rural Bangladesh."

9 John Bongaarts, Thomas Buettner, Gerhard Heilig, and François

Pelletier, "Has the HIV epidemic peaked?"

8 Barbara S. Mensch, Paul C. Hewett, Richard Gregory, and Stephane Helleringer, "Sexual behavior and STI/HIV status among adolescents in rural Malawi: An evaluation of the effect of interview mode on reporting."

7 John Bongaarts, "Fertility transitions in developing countries: Progress or stagnation?"

2007

6 Cynthia B. Lloyd, "The role of schools in promoting sexual and reproductive health among adolescents in developing countries."
5 Ann Biddlecom, Richard Gregory, Cynthia B. Lloyd, and Barbara S. Mensch, "Premarital sex and schooling transitions in four subSaharan African countries."

4 Sajeda Amin, John B. Casterline, and Laura Spess, "Poverty and fertility: Evidence and agenda."

3 Bussarawan Teerawichitchainan and James F. Phillips, "Ethnic differentials in parental health seeking for childhood illness in Vietnam."

2 Zachary Zimmer, Kim Korinek, John Knodel, and Napaporn Chayovan, "Support by migrants to their elderly parents in rural Cambodia and Thailand: A comparative study."

1 Sharon Ghuman and Cynthia B. Lloyd, "Teacher absence as a factor in gender inequalities in access to primary schooling in rural Pakistan.” 
Policy Research Division

working papers

2006

219 Cynthia B. Lloyd and Barbara S. Mensch, "Marriage and childbirth as factors in school exit: An analysis of DHS data from sub-Saharan Africa."

218 Ayaga A. Bawah, James F. Phillips, Martin Adjuik, Maya VaughanSmith, Bruce MacLeod, and Fred N. Binka, "The impact of immunization on the association between poverty and child survival: Evidence from Kassena-Nankana District of northern Ghana."

217 Zachary Zimmer, "Poverty, wealth inequality, and health among older adults in rural Cambodia."

216 John Bongaarts, "Late marriage and the HIV epidemic in sub-Saharan Africa."

215 John Bongaarts, "How long will we live?"

214 Zachary Zimmer, Toshiko Kaneda, and Laura Spess, "Urban versus rural mortality among older adults in China."

213 Paul Demeny and Geoffrey McNicoll, "The political demography of the world system, 2000-2050."

212 Monica Grant and Kelly Hallman, "Pregnancy-related school dropout and prior school performance in South Africa."

211 Kelly Hallman, Sara Peracca, Jennifer Catino, and Marta Julia Ruiz, "Multiple disadvantages of Mayan females: The effect of gender, ethnicity, poverty, and residence on education in Guatemala."
210 Geoffrey McNicoll, "Policy lessons of the East Asian demographic transition."

209 Cynthia B. Lloyd, Cem Mete, and Monica J. Grant, "The implications of changing educational and family circumstances for children's grade progression in rural Pakistan: 19972004." 